\section{BMJ Global Health}

\title{
Participant and narrative characteristics associated with host community members sharing experiences of peacekeeper- perpetrated sexual exploitation and abuse in the Democratic Republic of Congo
}

\author{
Susan Andrea Bartels (D) , ${ }^{1}$ Sandrine Lusamba, ${ }^{2}$ Sabine Lee ${ }^{3}$
}

\begin{abstract}
To cite: Bartels SA, Lusamba S, Lee S. Participant and narrative characteristics associated with host community members sharing experiences of peacekeeper-perpetrated sexual exploitation and abuse in the Democratic Republic of Congo. BMJ Global Health 2021;6:e006631. doi:10.1136/ bmjgh-2021-006631
\end{abstract}

Handling editor Stephanie M Topp

- Additional supplemental material is published online only. To view, please visit the journal online (http://dx.doi.org/10. 1136/bmjgh-2021-006631).

Received 16 June 2021 Accepted 17 September 2021

Check for updates

(C) Author(s) (or their employer(s)) 2021. Re-use permitted under CC BY-NC. No commercial re-use. See rights and permissions. Published by BMJ.

${ }^{1}$ Departments of Emergency Medicine and Public Health Sciences, Queen's University, Kingston, Ontario, Canada ${ }^{2}$ Solidarité Féminine Pour La Paix et le Développement Intégral, Beni, Democratic Republic of Congo ${ }^{3}$ Department of History, University of Birmingham, Birmingham, UK

Correspondence to Dr Susan Andrea Bartels; susanabartels@gmail.com

\section{ABSTRACT}

Introduction Peacekeeper-perpetrated sexual exploitation and abuse (SEA) in the Democratic Republic of Congo (DRC) account for $36 \%$ of the global reports of formal SEA allegations to the UN between 2007 and 2021. However, formally reported SEA represents only a fraction of that which occurs, and community experiences of peacekeeper-perpetrated SEA are likely different than those reflected in official UN documents.

Methods Using mixed-methods, cross-sectional data collected in the DRC in 2018, we used descriptive analysis and multivariate Poisson regression with robust error estimates to examine the participant and narrative characteristics associated with sharing an experience about peacekeeper-perpetrated SEA.

Results Participants in Bukavu (adjusted relative risk (aRR) $0.85,95 \% \mathrm{Cl} 0.79$ to 0.91 ) and Kalemie (aRR 0.75, $95 \% \mathrm{Cl} 0.69$ to 0.81 ) were less likely to share narratives about sexual interactions, while civilian UN personnel (aRR $1.16,95 \% \mathrm{Cl} 1.00$ to 1.34) were slightly more likely to be implicated in narratives about sexual interactions. Narratives in which the outcome was deemed fair to the woman/girl were more likely to be about sexual interactions (aRR 1.07, 95\% Cl 1.02 to 1.12). Both the regression analysis and the participants' interpretation of the shared narratives illustrated the significant role poverty played in SEA, suggesting that the outcomes of sexual interactions may have been deemed fair since affected women/girls were perceived to have benefited financially/ materially.

Conclusion There is significant variation between host communities in the likelihood of sharing narratives about SEA, which could prove useful for informing more targeted SEA prevention initiatives. Narratives about sexual interactions with UN personnel were more often deemed to have fair outcomes for the affected women/ girls, likely related to ongoing poverty in host communities and perceived financial/material gain. These findings highlight how extreme poverty may impact perceptions around informed consent as well as fairness and require further study. Perceptions around fair outcomes would disincentivise formal reporting, which needs to be considered when devising community-based complaint networks.

\section{WHAT IS ALREADY KNOWN?}

$\Rightarrow$ Despite endemic underreporting, the Democratic Republic of Congo has had high levels of peacekeeper-perpetrated sexual exploitation and abuse (SEA), recording over a third of all formal SEA allegations across all peace support operations.

$\Rightarrow$ Despite a policy of zero tolerance for SEA and strong discouragement of all sexual relations between UN peacekeepers and local communities, SEA is endemic and thus the effectiveness of the zerotolerance policy is questionable.

$\Rightarrow$ While host populations often envisage sexual relations with UN peacekeepers as a way out of poverty, such relations often exacerbate the cycle of poverty, especially where children are conceived.

\section{WHAT ARE THE NEW FINDINGS?}

$\Rightarrow$ Narratives about poverty were more likely to be about SEA, indicating that poverty is an indicator of the host population's vulnerability to SEA.

$\Rightarrow$ Given the central role of poverty, material/financial gain helps to explain why the outcomes were more likely to be perceived to be fair to the woman/girl when sexual interactions were involved.

$\Rightarrow$ Host community perceptions about agency and fairness are nuanced and are not congruent with all assumptions on which the UN's zero-tolerance policy is based, which may impact enforcement of the policy and SEA reporting by affected community members.

\section{INTRODUCTION}

\section{Armed conflict and sexual violence in the} Democratic Republic of Congo

The Democratic Republic of Congo (DRC) has experienced decades of armed conflict, insecurity and forced displacement, particularly in its eastern regions. ${ }^{1}$ Despite some improvements in the security situation in the last two decades following the 1999 signing of the Lusaka peace accord with neighbouring 


\section{WHAT DO THE NEW FINDINGS IMPLY?}

$\Rightarrow$ Empirical evidence of nuanced local perceptions related to peacekeeper-perpetrated SEA could influence updated and revised UN policies around the prevention of SEA.

$\Rightarrow$ A better understanding of local populations' reasons for engaging sexually with peacekeepers and perceptions of fairness could inform more effective peacekeeper SEA-prevention training, reporting mechanisms, and more survivor-centred investigation and support programmes.

countries, violence remained endemic, and sexual and gender-based violence has persisted at very high levels. ${ }^{2}$ The ongoing insecurity is a strong driver of displacement of approximately 4.5 million people within DRC and another estimated 800000 Congolese refugees who have migrated to other countries. ${ }^{3}$

Conflict and displacement in DRC have been characterised by pervasive and extreme forms of sexual violence often used as a strategic weapon of war. ${ }^{4-9}$ Using population-based data, a 2011 study estimated that up to 1.8 million women in the DRC had experienced lifetime rape, and up to 3.37 million women had experienced intimate partner sexual violence; the study also evidenced stark regional variation and all types of sexual violence, with such violence more common in the volatile eastern region of North Kivu in comparison with the western capital of Kinshasa. ${ }^{2}$

\section{Peace support operations in DRC}

DRC has hosted a peace support operation (PSO) since 1999. The original PSO, Mission de l'Organisation des Nations Unies en République Démocratique du Congoknown by its acronym MONUC-was tasked primarily with the support of the Lusaka Ceasefire Accord. MONUC was one of the largest PSOs ever deployed with approximately 20000 uniformed personnel at its peak ${ }^{10}$; yet, it was also widely criticised for being ineffective with respect to protecting civilians. ${ }^{1}$ In May 2010, following the assignment of a range of additional peace support tasks, the mission transitioned to Mission de l'Organisation des Nations Unies pour la Stabilisation en République Démocratique du Congo (MONUSCO) with an extended mandate to support stabilisation and consolidation of peace and to protect civilians. ${ }^{11}$ One of the most extensive and expensive PSOs in history, MONUSCO currently consists of almost 17500 actively deployed personnel. ${ }^{12}$

\section{Sexual exploitation and abuse by UN personnel}

Sexual exploitation and abuse (SEA) by peacekeepers in DRC was first reported in 2004. ${ }^{13}$ A majority of allegations involved sex with underage minors ${ }^{14}$ and some reports included UN employees videotaping themselves torturing and sexually abusing girls. ${ }^{15}$ Among the reports of SEA, transactional sex also featured prominently with stories of women and girls engaging sexually with peacekeepers in exchange for food or money. ${ }^{16}$ This is in gross violation of the UN's 'zero tolerance' policy which outlaws any exploitative or abusive behaviour on the part of UN personnel. Given the inherent high exploitative potential as a result of the socioeconomic and other power differentials between peacekeepers and local women, sexual interactions between those groups are prohibited in almost all cases. ${ }^{17}$

Despite the UN's 'zero tolerance' policy, peacekeeperperpetrated SEA continues in the DRC and beyond. The UN now publicly releases data on SEA allegations and among the 32 publicly identified missions with SEA complaints, MONUC and MONUSCO collectively have recorded 388 allegations between 2007 and 2021, contributing $36 \%$ of the total SEA reports in that timeframe.

\section{Objective}

There are significant concerns about peacekeeperperpetrated SEA in the DRC and it is important to recognise that allegations formally reported to the UN likely represent only a fraction of those that actually occur. ${ }^{18}$ Communities that host PSOs quite possibly have a different perspective of peacekeeper-perpetrated SEA than that reflected in official UN documents. This study aims to explore the link between those in the PSO host communities most likely to share experiences about peacekeeper-perpetrated SEA and their evaluations of the meaning of those experiences. In order to understand better the local perceptions of the interactions of women in host communities and peacekeepers, we therefore conducted the current analysis with the following two objectives: (1) to determine which participants were more likely to share a narrative about sexual interactions between UN peacekeepers and host community members; (2) to identify which narrative characteristics were associated with sharing a narrative describing sexual interactions between local civilians and UN personnel.

\section{METHODS}

This cross-sectional, mixed qualitative-quantitative study was conducted across six locations in the DRC between May and July 2018. We choose a mixed-methods approach to collect richer and more comprehensive data and to give a voice to study participants, ensuring that findings were grounded in participants' experiences. ${ }^{19}$ We used a convergence model triangulation design as described by Creswell and Plano Clark ${ }^{20}$ in which the quantitative and qualitative data were collected concurrently and were assigned equal weighting in the analysis. We believe this approach offered the advantage of being able to corroborate the quantitative findings with the more nuanced qualitative results, ensuring that the research generated better substantiated conclusions.

\section{Location and participant selection}

Six UN bases in eastern DRC were purposively selected based on available data regarding the sizes, troop and police contributing country staffing, years of operation and geographical variation to represent the north and south as well as urban and rural regions. Within a $30 \mathrm{~km}$ 
perimeter of each UN base, a convenience sample of prospective participants were approached in public locations such as market areas, street vendors, shops and public transportation stops/depots. Individuals had to be 13 years of age or older to participate.

\section{SenseMaker survey}

SenseMaker is a narrative capture tool that extracts meaning from micro-narratives shared by participants on a topic of interest (in this case interactions between Congolese women/girls and MONUSCO personnel). The SenseMaker application does this by empowering participants to interpret their experiences by responding to interpretation questions, which extracts participants' own understanding or perspectives in a quantifiable manner. ${ }^{21}$ Participants were asked to audio record a short narrative (referred to here as a 'micro-narrative' since they are often brief with audio recordings of 2-3 min on average) in response to one of three prompting questions: $a$. Think of a woman or girl who lives near this UN base. Share a specific story that illustrates the best or worst thing for her because of living near the base; $b$. Think of a woman or girl who has interacted with UN personnel in your community. Share a specific example of a positive or negative experience that she has had as a result of her interaction with a UN personnel; or c. Think of a woman or girl in this community. Tell a story about how the presence of UN workers has helped or harmed her. For the purpose of this work, 'shared experience' or 'shared micro-narrative' refers to this brief story audio recorded by participants in response to the open-ended prompting question. Participants then interpreted the shared experiences by responding to a series of predefined questions, plotting their perspectives between two (dyads) or three (triads) possible options (online supplemental appendix 1). Multiple-choice questions asked demographic information and helped to contextualise the shared story (eg, who was the story about?). The SenseMaker survey did not prompt for narratives about sexual relations and instead allowed experiences to emerge more naturally. The prompts were open-ended by design and were intended to trigger recollection of a local woman or girl's experience interacting with foreign UN peacekeepers. The full survey is provided in online supplemental appendix 2.

The SenseMaker survey was written in English, translated to Lingala and Swahili and then back translated by an independent translator to check for accuracy. The survey was pilot tested in the DRC among 24 participants and the questions were refined accordingly.

\section{Local partners}

This research was implemented in collaboration with two local organisations. Solidarité Féminine Pour la Paix et le Développement Intégral (SOFEPADI) is a Congolese non-governmental organisation that advocates for equal access to social justice for women and girls. SOFEPADI was instrumental in informing the cultural aspects of the research design and survey development.
Multidisciplinary Association for Research and Advocacy in the Kivus by United Junior Academics (Marakuja) is a non-profit organisation of Congolese researchers with extensive experience implementing large-scale research projects in the DRC since 2009.

\section{Data collection}

A team of 12 research assistants (RAs) from Marakuja and SOFEPADI conducted all interviews. The female SOFEPADI RAs had extensive experience working with survivors of sexual and gender-based violence. All RAs completed a 5-day training immediately prior to data collection. Training topics included SenseMaker methodology, research ethics, a detailed question-by-question review of the survey, data upload, as well as management of adverse events and programme referrals.

All interviews were conducted in either Lingala or Swahili. Shared micro-narratives were audio recorded and then interpretation questions were answered by the participant on a study tablet. Participants could share more than one micro-narrative if they chose and thus the total number of micro-narratives exceeds the number of unique participants. All data were collected on iPad Mini 4's using the SenseMaker application and data were uploaded to the secure Cognitive Edge server. Recorded micro-narratives were transcribed and then translated from Lingala/Swahili to English by native Lingala/ Swahili speakers respectively.

\section{Analysis}

SenseMaker data were exported to Tableau (V.2020.4) where collective plots (with all participants responses on the same figure) were analysed visually to identify data patterns such as clusters of responses in one extreme or another, outliers, and so on. ${ }^{21}$ Triad and dyad data were disaggregated based on whether the shared micronarrative was about or not about sexual relations since sexual interactions between UN peacekeepers and host community women/girls was the a priori topic of interest. Triad and dyad questions where, based on visual inspection, the pattern of responses appeared to differ between micro-narratives about sexual relations and micro-narratives not about sexual relation (responses clustered in different areas for example) were selected for statistical analysis. For the dyad data, graphically represented as histograms, SPSS (IBM SPSS Statistics V.26.0.0.0) was used to analyse the collective areas under the bars for each subgroup with the Kruskal-Wallis $\mathrm{H}$ test and $\chi^{2}$ tests to determine if the bar areas were statistically different between groups. ${ }^{22}{ }^{23}$ Post hoc analysis with Dunn's test identified which sub-groups differed from others. Dyad distribution of responses are presented as violin plots to illustrate the different response patterns, with an asterisk indicating the overall mean for each sub-group. For the triad data, R Scripts (R V.3.4.0) was used to generate geometric means for each subgroup. $\mathrm{R}$ Scripts was also used to generate $95 \%$ CIs, which are presented as confidence ellipses around the geometric 
means. ${ }^{24}{ }^{25}$ Geometric means were deemed statistically different if their $95 \%$ confidence ellipses did not overlap with others.

Descriptive statistics were conducted in SPSS (IBM SPSS Statistics V.26.0.0.0) using $\chi^{2}$ tests to identify differences between subgroups. Multivariate Poisson regression with robust error estimates ${ }^{26}$ was used to examine which participant and micro-narrative characteristics predicted whether a micro-narrative was about sexual interactions between UN personnel and host community members. The analysis controlled for participant age/ marital status/level of education, household income, location, who the micro-narrative was about, fairness of outcome, feelings, emotional tone, role of UN personnel in the micro-narrative and whether the micro-narrative was about poverty. For all analyses, $p$ values $<0.05$ were taken to be statistically significant.

After patterns of perspectives were identified in the quantitative data, accompanying narratives were reviewed to facilitate interpretation of the statistical findings. A series of representative quotes were then chosen for inclusion to illustrate the main quantitative results.

\section{Ethics considerations}

After reviewing the informed consent in Lingala/ Swahili, respondents indicated their willingness to participate by tapping a consent box on the tablet. No identifying information was collected, and all interviews were conducted privately. No financial compensation or other incentive was offered for participation. Individuals as young as age 13 were included as previous evidence suggested that they are often specifically targeted for SEA by peacekeepers and aid workers. ${ }^{27}$ On that basis, it was deemed unethical to not include their experiences and perspectives. Parental consent was not sought given that the survey was open-ended and did not ask direct questions about sexual interactions. This is consistent with recent guidelines which suggest that asking parental consent can introduce bias and create conflict between adolescents and parents. ${ }^{28}$ No participants dropped out of the study due to distress. Emotional support was provided if needed at the time of the interview and any participant who was thought to require counselling or follow-up services was referred to SOFEPADI. Each team had a SOFEPADI representative who had the training and experience to provide on-site support if needed.

\section{Public involvement}

Based on years of experience working closely with survivors of SEA, SOFEPADI helped to develop the survey and represented survivors' collective interests in the research's design and implementation. Some early results were presented back to SEA survivors in focus group discussions in March 2020, with a plan to continue this engagement once COVID-19 restrictions ease.

\section{RESULTS}

A total of 2856 self-interpreted micro-narratives about interactions between MONUSCO peacekeepers and local women/girls were collected from 2499 unique participants. Participant demographics and micro-narrative characteristics are provided in tables 1 and 2, respectively, disaggregated by whether the micro-narrative was about sexual interactions.

There was a slight preponderance of female participants $(52.3 \%)$, most participants were aged 18 to $34(69.1 \%)$ and the sample was relatively educated, with $44 \%$ having at least some secondary education and $29.6 \%$ having post-secondary education/technical training (table 1). Micro-narratives about sexual interactions differed from those not about sexual interactions with regards to age, marital status and education level for the participant, household income, and location.

As demonstrated in table 2, a majority of the micronarratives were shared about a non-family member $(54.9 \%)$ and were attributed negative emotions $(61.6 \%)$. Almost half of participants indicated that the outcome of the interaction was not fair to the woman/girl involved (48.1\%). Micro-narratives about sexual interactions differed from those not about sexual interactions based on the protagonist in the narrative (ie, who the story was about) and feelings about the narrative (positive, negative or mixed). There was also a statistically significant difference between micro-narratives about or not about sexual interactions with respect to the role of the UN personnel involved (soldier, civilian, aid worker, police or other). Finally, whether the outcome was perceived to be fair to the woman/girl in the shared experience differed based on whether the micro-narrative was about sexual interactions. From a research perspective, the concept of fairness was broadly intended to capture opinions about power differentials between UN personnel and host community women/girls, in addition to perspectives about who benefits from these interactions. However, as is intentional with a 'SenseMaking' approach, fairness was not defined in the survey and instead it was left open for individual participants to interpret.

Multivariate Poisson regression with robust error estimates identified the participant and narrative characteristics associated with sharing a story about sexual interactions (table 3). Married participants were less likely to share a narrative about sexual interactions (adjusted relative risk (aRR) $0.87,95 \%$ CI 0.81 to 0.94 ) as were participants in Bukavu (aRR 0.85, 95\% CI 0.79 to 0.91) and Kalemie (aRR $0.75,95 \%$ CI 0.69 to 0.81 ). First-person narratives were less likely to be about sexual interactions (aRR $0.82,95 \%$ CI 0.73 to 0.92 ) while narratives shared about an individual known to the participant (aRR 1.14, $95 \%$ CI 1.05 to 1.25 ) were more likely to be about sexual interactions.

Narratives in which outcomes were deemed fair to the woman/girl were more likely to be about sexual interactions (aRR 1.07, 95\% CI 1.02 to 1.12). Examination of the accompanying narratives revealed that this finding 
Table 1 Study population characteristics disaggregated by whether micro-narratives were about sexual relations

\begin{tabular}{|c|c|c|c|c|c|c|c|}
\hline & \multicolumn{2}{|c|}{$\begin{array}{l}\text { Total } \\
\text { (\% of } \mathrm{N}=2856 \text { ) }\end{array}$} & \multicolumn{2}{|c|}{$\begin{array}{l}\text { About sexual relations } \\
(\% \text { of } \mathrm{N}=2078)\end{array}$} & \multicolumn{2}{|c|}{$\begin{array}{l}\text { Not about sexual relations } \\
\text { ( } \% \text { of } N=778 \text { ) }\end{array}$} & P value* \\
\hline \multicolumn{8}{|l|}{ Participant's sex } \\
\hline Female & 1495 & 52.3 & 1074 & 51.7 & 421 & 54.1 & \multirow[t]{4}{*}{0.252} \\
\hline Male & 1360 & 47.6 & 1003 & 48.3 & 357 & 45.9 & \\
\hline Prefer not to say & 1 & 0.0 & 1 & 0.0 & 0 & 0.0 & \\
\hline Total & 2856 & & 2078 & & 778 & & \\
\hline \multicolumn{8}{|l|}{ Participant's age } \\
\hline $13-17$ & 222 & 7.8 & 162 & 7.8 & 60 & 7.7 & \multirow[t]{7}{*}{0.004} \\
\hline $18-24$ & 996 & 34.9 & 751 & 36.1 & 245 & 31.5 & \\
\hline $25-34$ & 977 & 34.2 & 723 & 34.8 & 254 & 32.6 & \\
\hline $35-44$ & 421 & 14.7 & 281 & 13.5 & 140 & 18.0 & \\
\hline 45 and older & 228 & 8.0 & 153 & 7.4 & 75 & 9.6 & \\
\hline Prefer not to say & 12 & 0.4 & 8 & 0.4 & 4 & 0.5 & \\
\hline Total & 2856 & & 2078 & & 778 & & \\
\hline \multicolumn{8}{|l|}{ Participant's marital status } \\
\hline Single/never married & 1382 & 48.4 & 1099 & 52.9 & 283 & 36.4 & \multirow[t]{5}{*}{$<0.001$} \\
\hline Married/living with partner & 1247 & 43.7 & 802 & 38.6 & 445 & 57.2 & \\
\hline Divorced/separated/widowed & 222 & 7.8 & 172 & 8.3 & 50 & 6.4 & \\
\hline Prefer not to say & 5 & 0.2 & 5 & 0.2 & 0 & 0.0 & \\
\hline Total & 2856 & & 2078 & & 778 & & \\
\hline \multicolumn{8}{|c|}{ Participant's level of formal education } \\
\hline None & 200 & 7.0 & 138 & 6.6 & 62 & 8.0 & \multirow[t]{6}{*}{$<0.001$} \\
\hline Primary school & 540 & 18.9 & 387 & 18.6 & 153 & 19.7 & \\
\hline Secondary school & 1257 & 44.0 & 862 & 41.5 & 395 & 50.8 & \\
\hline University/technical training & 844 & 29.6 & 678 & 32.6 & 166 & 21.3 & \\
\hline Other/prefer not to say & 15 & 0.5 & 13 & 0.6 & 2 & 0.3 & \\
\hline Total & 2856 & & 2078 & & 778 & & \\
\hline \multicolumn{8}{|c|}{ Participant's household income level } \\
\hline Poor & 822 & 28.8 & 558 & 26.9 & 264 & 33.9 & \multirow[t]{4}{*}{$<0.001$} \\
\hline Average & 1358 & 47.5 & 968 & 46.6 & 390 & 50.1 & \\
\hline Well-off & 676 & 23.7 & 552 & 26.6 & 124 & 15.9 & \\
\hline Total & 2856 & & 2078 & & 778 & & \\
\hline \multicolumn{8}{|l|}{ Area collected } \\
\hline Kisangani & 563 & 19.7 & 496 & 23.9 & 67 & 8.6 & \multirow[t]{7}{*}{$<0.001$} \\
\hline Bunia & 538 & 18.8 & 448 & 21.6 & 90 & 11.6 & \\
\hline Goma & 511 & 17.9 & 404 & 19.4 & 107 & 13.8 & \\
\hline Kalemie & 500 & 17.5 & 205 & 9.9 & 295 & 37.9 & \\
\hline Bukavu & 492 & 17.2 & 315 & 15.2 & 177 & 22.8 & \\
\hline Beni & 252 & 8.8 & 210 & 10.1 & 42 & 5.4 & \\
\hline Total & 2856 & & 2078 & & 778 & & \\
\hline
\end{tabular}

${ }^{*}$ Pearson $\chi^{2}$. Analyses excluded the following sub-categories: Prefer not to say, Not sure, Don't know, Missing.

was explained primarily through financial or material gain on behalf of the woman/girl and/or her family as a result of the sexual interactions. The following quote is a typical example from the micro-narrative data and is included to highlight the intersection between perceived fairness and financial/material gain as a result of transactional sex or sex work with UN peacekeeping personnel: 
Table 2 Micro-narrative characteristics disaggregated by whether the micro-narratives were about sexual relations

\begin{tabular}{|c|c|c|c|c|c|c|c|}
\hline & \multicolumn{2}{|c|}{$\begin{array}{l}\text { Total }(\% \text { of } \\
\mathrm{N}=2856)\end{array}$} & \multicolumn{2}{|c|}{$\begin{array}{l}\text { About sexual relations ( } \% \\
\text { of } \mathrm{N}=2078 \text { ) }\end{array}$} & \multicolumn{2}{|c|}{$\begin{array}{l}\text { Not about sexual relations } \\
\text { (\% of } \mathrm{N}=778)\end{array}$} & $P$ value* \\
\hline \multicolumn{8}{|c|}{ Who the micro-narrative was about } \\
\hline $\mathrm{Me}$ & 489 & 17.1 & 229 & 11.0 & 260 & 33.4 & \multirow[t]{6}{*}{$<0.001$} \\
\hline Family member & 447 & 15.7 & 337 & 16.2 & 110 & 14.1 & \\
\hline Someone else I know & 1567 & 54.9 & 1347 & 64.8 & 220 & 28.3 & \\
\hline Someone I heard & 342 & 12.0 & 162 & 7.8 & 180 & 23.1 & \\
\hline Prefer not to say & 11 & 0.4 & 3 & 0.1 & 8 & 1.0 & \\
\hline Total & 2856 & & 2078 & & 778 & & \\
\hline \multicolumn{8}{|l|}{ Outcome fair to woman/girl } \\
\hline Unfair & 1374 & 48.1 & 1110 & 53.4 & 264 & 33.9 & \multirow[t]{5}{*}{$<0.001$} \\
\hline Neutral & 60 & 2.1 & 36 & 1.7 & 24 & 3.1 & \\
\hline Fair & 1254 & 43.9 & 874 & 42.1 & 380 & 48.8 & \\
\hline Not sure & 168 & 5.9 & 58 & 2.8 & 110 & 14.1 & \\
\hline Total & 2856 & & 2078 & & 778 & & \\
\hline \multicolumn{8}{|c|}{ Feelings about the micro-narrative $\dagger$} \\
\hline Positive & 770 & 27.0 & 392 & 18.9 & 378 & 48.6 & \multirow[t]{5}{*}{$<0.001$} \\
\hline Negative & 1760 & 61.6 & 1408 & 67.8 & 352 & 45.2 & \\
\hline Mixed feelings & 117 & 4.1 & 90 & 4.3 & 27 & 3.5 & \\
\hline Missing data & 209 & 7.3 & 188 & 9.0 & 21 & 2.7 & \\
\hline Total & 2856 & & 2078 & & 778 & & \\
\hline \multicolumn{8}{|l|}{ Role of UN personnel } \\
\hline Armed/unarmed soldier & 1978 & 69.3 & 1467 & 70.6 & 511 & 65.7 & \multirow[t]{7}{*}{$<0.001$} \\
\hline Civilian & 439 & 15.4 & 339 & 16.3 & 100 & 12.9 & \\
\hline Worked for NGO & 38 & 1.3 & 23 & 1.1 & 15 & 1.9 & \\
\hline UN police & 49 & 1.7 & 43 & 2.1 & 6 & 0.8 & \\
\hline Other & 130 & 4.6 & 54 & 2.6 & 76 & 9.8 & \\
\hline Don’t know & 222 & 7.8 & 152 & 7.3 & 70 & 9.0 & \\
\hline Total & 2856 & & 2078 & & 778 & & \\
\hline \multicolumn{8}{|l|}{ Nationality of UN personnelł } \\
\hline Sub-Saharan Africa & 1124 & 39.4 & 890 & 42.8 & 234 & 30.1 & \multirow[t]{4}{*}{0.180} \\
\hline $\begin{array}{l}\text { Not from sub-Saharan } \\
\text { Africa }\end{array}$ & 835 & 29.2 & 640 & 30.8 & 195 & 25.1 & \\
\hline Missing data§ & 897 & 31.4 & 548 & 26.4 & 349 & 44.9 & \\
\hline Total & 2856 & & 2078 & & 778 & & \\
\hline \multicolumn{8}{|c|}{ Micro-narrative about poverty } \\
\hline Not about poverty & 1447 & 50.6 & 1129 & 54.3 & 318 & 40.9 & \multirow[t]{4}{*}{$<0.001$} \\
\hline About poverty & 790 & 27.7 & 685 & 33.0 & 105 & 13.5 & \\
\hline Missing & 619 & 21.7 & 264 & 12.7 & 355 & 45.6 & \\
\hline Total & 2856 & & 2078 & & 778 & & \\
\hline
\end{tabular}

Continued 
Table 2 Continued

\begin{tabular}{|c|c|c|c|c|c|c|c|}
\hline \multirow[b]{2}{*}{$\begin{array}{l}\text { Best or worse } \\
\text { experience near UN } \\
\text { base }\end{array}$} & \multicolumn{2}{|c|}{$\begin{array}{l}\text { Total (\% of } \\
\mathrm{N}=2856)\end{array}$} & \multicolumn{2}{|c|}{$\begin{array}{l}\text { About sexual relations ( } \% \\
\text { of } \mathrm{N}=2078 \text { ) }\end{array}$} & \multicolumn{2}{|c|}{$\begin{array}{l}\text { Not about sexual relations } \\
(\% \text { of } \mathrm{N}=778)\end{array}$} & \multirow{2}{*}{$\begin{array}{l}\text { P value }^{*} \\
<0.001\end{array}$} \\
\hline & 784 & 27.5 & 672 & 32.3 & 112 & 14.4 & \\
\hline $\begin{array}{l}\text { Positive or negative } \\
\text { interactions with UN }\end{array}$ & 1181 & 41.4 & 1083 & 52.1 & 98 & 12.6 & \\
\hline $\begin{array}{l}\text { UN presence helped or } \\
\text { harmed }\end{array}$ & 891 & 31.2 & 323 & 15.5 & 568 & 73.0 & \\
\hline Total & 2856 & & 2078 & & 778 & & \\
\hline
\end{tabular}

*Pearson $\chi^{2}$. Analyses excluded the following sub-categories: Prefer not to say, Not sure, Don't know, Missing.

†Positive: Encouraged, Good, Happy, Hopeful, Relived, Satisfied. Negative: Afraid, Angry, Disappointed, Embarrassed, Frustrated, Sad, Worried.

¥Sub-Saharan Africa: DRC, Ghana, Senegal, Sierra Leone, South Africa, Tanzania. Not from sub-Saharan Africa: Bangladesh, Egypt, India, Morocco, Nepal, Pakistan, Uruguay.

§Includes data from the 'Other' category in dataset. This category contains both sub-Saharan and non-sub-Saharan countries.

We had a habit of going to the MONUSCO camp at MUBAMBIRO when we were still prostitutes. We specifically had to go there every day to have sex with men in exchange for money because we are from poor families. Since poverty was very extreme, parents were dying. Then, we could go to MONUSCO for that.

Unmarried female in Goma, aged 18-24, who reported that the outcome was somewhat fair to the woman/girl [ID438]

In contrast, other participants believed strongly that the outcomes of sexual interactions with UN personnel were completely unfair as per the example in figure 1. The quote in figure 1 is also representative of the data overall and is included to bring forth the perspective that when children were conceived from the sexual interactions and later abandoned by the peacekeeper fathers, the outcomes were often deemed more unfair by participants. In these instances, the responsibility (financial and otherwise) to raise the children was left with the mother, who often struggled to meet those obligations.

Narratives attributed all positive feelings were less likely to be about sexual interactions (aRR 0.88 , 95\% CI 0.80 to 0.96 ). The following quote is a representative example of transactional sex between girls and UN soldiers who solicited sex in exchange for small amounts of money, with a resulting pregnancy for one of the girls. This micro-narrative is included to illustrate how schoolgirls engaged sexually with soldiers stationed at a base near their school.

As we are studying in the vicinity of MONUSCO base, those soldiers used to call girls telling them, "JIGI JIGI, one dollar" which means if a girl accepts to have intimate relations with them, they gave her 1 or 10 dollars. Unfortunately, three girlfriends of mine who were studying at a school in the vicinity of that base were going out with MONUSCO soldiers, among whom one girl was made pregnant. She gave birth to a child without nationality or father, but she knows that the father of her child was a MONUSCO soldier from Bangladesh.
Unmarried male in Bunia, aged 25-34, who reported that this experience with Bangladeshi soldiers made him feel angry [ID2855]

Narratives that were about poverty were more likely to be about sexual interactions (aRR 1.08, 95\% CI 1.04 to 1.12) as were narratives that were about civilian UN personnel (aRR 1.16, 95\% CI 1.00 to 1.34).

To triangulate these quantitative findings with the SenseMaker data, in which participants interpreted the experiences shared in their narratives, we also analysed the triad that considered poverty as a possible response. For example, in the triad shown in figure 1, participants were asked what their narratives were about. Each small grey dot represents an individual participant's response. The larger red and green dots represent geometric means for the 'about sexual interactions' and 'not about sexual interactions' subgroups, respectively. Also, 95\% CIs are provided for each geometric mean and are presented graphically as confidence ellipses. If the confidence ellipses for two subgroups do not overlap, participants in those subgroups responded in a statistically different way on that particular question. In the triad illustrated in figure 1, micro-narratives about sexual interaction were statistically more likely to be interpreted as being about poverty. An illustrative quote is provided with the accompanying triad response highlighted, providing an example of how perceptions around fairness were linked to poverty and raising peacekeeper-fathered children.

Figure 2 provides an example of a dyad that asked participants who had initiated the interaction described in the shared micro-narrative. The shape of each figure for the about sexual interaction and not about sexual interactions subgroups illustrates the distribution of participants' responses. The data demonstrate that participants were more likely to report that the peacekeeping personnel was the initiator when the interaction was sexual in nature as shown by the wide base to the left of the top figure in red. The mean response for 
Table 3 Multivariate Poisson regression* to identify participant and narrative characteristics associated with sharing a story about sexual interactions

\begin{tabular}{|c|c|c|c|}
\hline & aRRt & $95 \% \mathrm{Cl}$ & $P$ value \\
\hline \multicolumn{4}{|l|}{ Participants's age } \\
\hline 13 to 17 & 1.01 & (0.91 to 1.14$)$ & 0.804 \\
\hline 18 to 24 & 0.99 & (0.89 to 1.09$)$ & 0.785 \\
\hline 25 to 34 & 1.05 & (0.96 to 1.16$)$ & 0.296 \\
\hline 35 to 44 & 1.06 & (0.96 to 1.18$)$ & 0.246 \\
\hline 45 and older & 1.00 & & \\
\hline \multicolumn{4}{|l|}{ Participant's marital status } \\
\hline Single/never married & 0.99 & (0.92 to 1.07$)$ & 0.819 \\
\hline Married/living with partner & 0.87 & (0.81 to 0.94$)$ & 0.001 \\
\hline Divorced/separated/widowed & 1.00 & & \\
\hline \multicolumn{4}{|l|}{ Participant's level of education } \\
\hline None & 0.94 & (0.85 to 1.04$)$ & 0.208 \\
\hline Primary school & 1.05 & (0.98 to 1.13$)$ & 0.163 \\
\hline Secondary school & 1.00 & (0.95 to 1.05$)$ & 0.963 \\
\hline University/technical training & 1.00 & & \\
\hline \multicolumn{4}{|c|}{ Participant's household income level } \\
\hline Poor & 0.95 & (0.89 to 1.01$)$ & 0.114 \\
\hline Average & 0.98 & (0.93 to 1.03$)$ & 0.489 \\
\hline Well-off & 1.00 & & \\
\hline \multicolumn{4}{|l|}{ Location } \\
\hline Beni & 1.00 & (0.93 to 1.06$)$ & 0.883 \\
\hline Bukavu & 0.85 & (0.79 to 0.91$)$ & $<0.001$ \\
\hline Bunia & 0.98 & (0.92 to 1.05$)$ & 0.593 \\
\hline Goma & 1.02 & (0.94 to 1.09 ) & 0.672 \\
\hline Kalemie & 0.75 & (0.69 to 0.81$)$ & $<0.001$ \\
\hline Kisangani & 1.00 & & \\
\hline \multicolumn{4}{|l|}{ Who micro-narrative was about } \\
\hline $\mathrm{Me}$ & 0.82 & (0.73 to 0.92$)$ & 0.001 \\
\hline Family member & 1.05 & (0.96 to 1.16$)$ & 0.300 \\
\hline Someone else I know & 1.14 & (1.05 to 1.25$)$ & 0.002 \\
\hline Someone I heard & 1.00 & & \\
\hline \multicolumn{4}{|l|}{ Micro-narrative emotional tone } \\
\hline Positive & 0.92 & (0.87 to 0.98$)$ & 0.007 \\
\hline Negative & 1.00 & & \\
\hline \multicolumn{4}{|l|}{ Outcome fair to woman/girl } \\
\hline Fair & 1.07 & (1.02 to 1.12$)$ & 0.003 \\
\hline Neutral & 1.05 & (0.86 to 1.28$)$ & 0.628 \\
\hline Unfair & 1.00 & & \\
\hline \multicolumn{4}{|l|}{ Feelings about the micro-narrative } \\
\hline Positive & 0.88 & (0.80 to 0.96$)$ & 0.006 \\
\hline Negative & 0.98 & (0.91 to 1.06$)$ & 0.567 \\
\hline Mixed & 1.00 & & \\
\hline \multicolumn{4}{|l|}{ Role of UN personnel } \\
\hline Armed/unarmed soldier & 1.14 & (1.00 to 1.30$)$ & 0.056 \\
\hline
\end{tabular}


Table 3 Continued

\begin{tabular}{|c|c|c|c|}
\hline & aRR† & $95 \% \mathbf{C l}$ & $P$ value \\
\hline Civilian & 1.16 & $(1.00$ to 1.34$)$ & 0.049 \\
\hline UN Police & 1.19 & (0.99 to 1.44$)$ & 0.059 \\
\hline Worked for NGO & 1.15 & (0.91 to 1.44$)$ & 0.245 \\
\hline Other & 1.00 & & \\
\hline \multicolumn{4}{|l|}{ Poverty } \\
\hline About poverty & 1.08 & (1.04 to 1.12$)$ & $<0.001$ \\
\hline Not about poverty & 1.00 & & \\
\hline \multicolumn{4}{|l|}{ Story prompt } \\
\hline Experience of females near UN base & 1.69 & (1.55 to 1.85$)$ & $<0.001$ \\
\hline Experience of females interacted with UN personnel & 1.76 & (1.61 to 1.92$)$ & $<0.001$ \\
\hline UN presence help or harm females & 1.00 & & \\
\hline
\end{tabular}

*Variables were included if $\mathrm{p}<0.1$ in demographic and story characteristics tables. $\mathrm{N}=1781$.

taRR, adjusted relative risk with all other variables in the table controlled for.

each subgroup is highlighted with an asterisk, which also demonstrated that UN personnel were more likely to have initiated the interactions when they were sexual in nature $(\mathrm{p}<0.001)$. In the included quote, a 15-year-old girl had been raped by a peacekeeper. While rape was mentioned in our dataset, it was far less frequent than transactional sex and sex work. When rape did occur, it was often opportunistic on the part of the perpetrator and in the context of a girl or young woman encountering a peacekeeper in the community. We include this narrative to recognise that while much of the SEA described was more exploitative in nature, sexual violence and abuse also occurred.

\section{DISCUSSION}

Using mixed-methods data from six eastern DRC communities that host MONUSCO peacekeeping personnel, we present data to better understand which factors were predictive of sharing a narrative about sexual

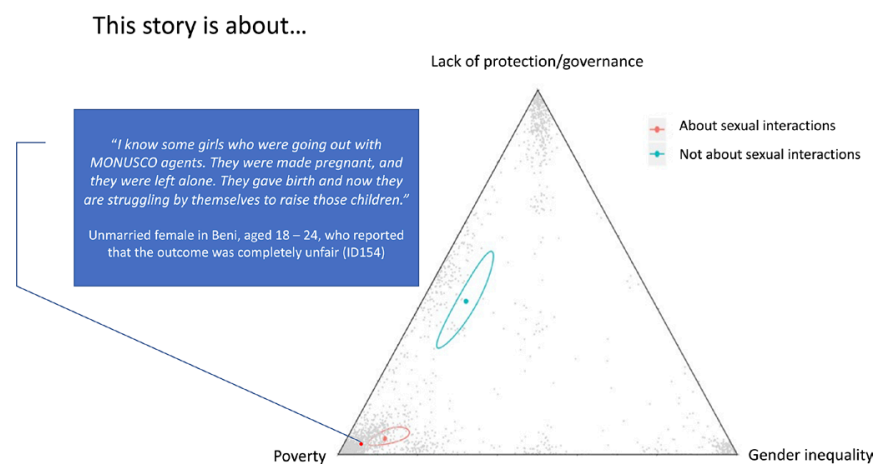

Figure 1 Each small grey dot represents an individual participant's response. The red and green dots represent geometric means for the 'about sexual interactions' and 'not about sexual interactions' subgroups, respectively, each with a surrounding 95\% confidence ellipse. An illustrative quote is provided with the accompanying triad response highlighted. interactions. To the best of our knowledge, this is the largest mixed-methods study to examine UN personnelperpetrated SEA. Participants in Bukavu and Kalemie, in South Kivu and Tanganyika Provinces, respectively, were less likely to share a narrative about sexual interactions, as were married participants, at all six locations. UN civilian personnel were more likely to be implicated in narratives about sexual interactions. Unexpectedly, narratives in which the outcome was deemed fair by the participant were more likely to be about sexual interactions. This finding appeared to be related to financial gain and was supported by both the regression analysis as well as the triad data, which illustrated the significant role that poverty contributed to sexual interactions between UN personnel and host community women/girls. Finally, participants sharing narratives about sexual interactions

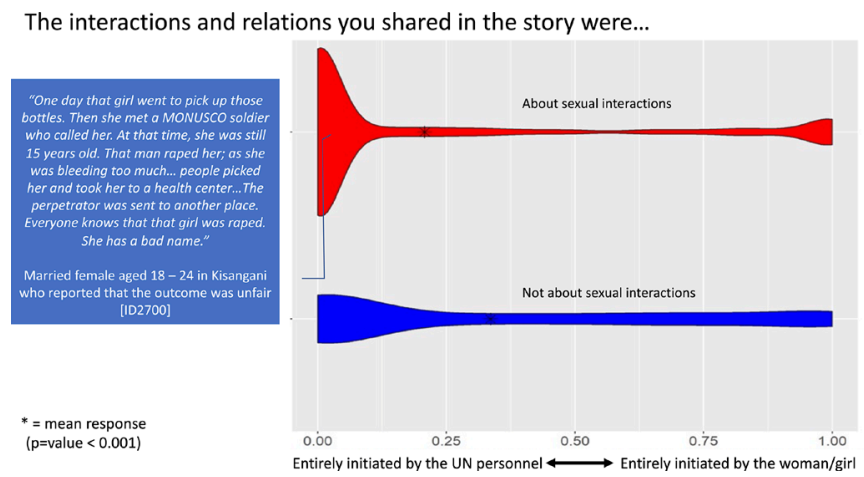

Figure 2 Dyad asking who had initiated the interaction described in the micro-narrative shared by the participant. Plots of responses along the spectrum of interaction 'entirely initiated by the UN personnel' versus 'entirely initiated by the woman/girl' disaggregated by whether the story was about sexual interactions or not, with an illustrative quote. Asterisks indicate the overall mean for each sub-group and highlight that peacekeepers were more likely to initiate interactions that were sexual in nature. 
were more likely to indicate that the shared experience was positive and that interaction was entirely initiated by the UN personnel.

Earlier research has also examined predictors of sexual interactions between UN peacekeeping personnel and host community members. Using the UN's own publicly available data between 1999 and 2010, Nordås and Rustad identified several mission-level factors predictive of SEA allegations including PSO mandates that were more humanitarian in nature and more focused on gender equality, higher violence levels within the armed conflict and larger mission size. ${ }^{29}$ Host-country factors positively associated with SEA allegations against UN personnel included high levels of sexual violence before the conflict, absence of spousal rape law and low GDP per capita. ${ }^{29}$ Neudorfer found similar results, reporting high levels of sexual violence in host country were positively and significantly correlated with the number of SEA allegations against peacekeepers. ${ }^{16}$ She also reported that poor supervision of peacekeepers was associated with SEA allegations, while introduction of reporting and investigation mechanisms and host community education and empowerment reduced reports of SEA. ${ }^{16}$ Furthermore, in his analysis of PSO data from 2007 to 2014, Moncrief similarly found that higher host-country GDP per capita was significantly associated with fewer SEA allegations. ${ }^{30}$ Moncrief also reported that larger mission size and disciplinary erosion (using reported non-SEA misconduct as a proxy) were positively associated with a higher number of SEA allegations. ${ }^{30}$

Unlike the aforementioned studies which used publicly available UN data, research among host community members in Haiti (similar approach to that taken here) documented that individuals living in rural areas were more likely to share a narrative about sexual misconduct by UN personnel in comparison with those living in more urban areas. ${ }^{31}$ The current findings contradict those in Haiti since participants in the smallest and most remote of the interview locations, Kalemie, were less likely to share a narrative about sexual interactions. Participants in Bukavu were similarly less likely to share a narrative about sexual interactions with UN personnel although it is a large metropolitan area and so population/rurality do not explain these results. In addition, other previously identified host community predictors of sexual misconduct (ie, spousal rape laws, low GDP per capital and high pre-existing levels of sexual violence) are not known, to the best of our knowledge, to be different in Bukavu and Kalemie than in the other four locations included in the study. Therefore, in DRC, urban/rural differences do not appear to be a reliable predictor of where narratives about peacekeeper-perpetrated SEA were shared.

What does seem to be more consistent across PSOs and locations is that underlying poverty and lack of socioeconomic empowerment for host community women/girls is a key driver of sexual interactions with UN peacekeeping personnel. In this regard, our results are well aligned with earlier research in Haiti, ${ }^{32-35}$ Liberia, ${ }^{36}{ }^{37}$ Sierra Leone and DRC..$^{38}$ With a GDP per capita of US $\$ 580.7,{ }^{39}$ DRC is a low-income country with $77 \%$ of its population living below the poverty line of US $\$ 1.90 /$ day. ${ }^{40}$ In this context, peacekeeping personnel are comparatively wealthy. In fact, it has been estimated that foreign peacekeepers earn 500-1000 times the average local salary, ${ }^{41}$ and this may be even more true for eastern DRC which continues to face ongoing instability. This significant wage differential influences the local economy, and given that peacekeepers are predominantly male, it does so in a gendered way, often increasing the likelihood of coercion, transactional sex and sex work. ${ }^{41}$ However, it was unexpected that narratives in which the outcome was deemed fair to the woman/girl would be more likely to be about sexual interactions with peacekeepers. Given the central role of host community poverty in initiating and perpetuating sexual misconduct by UN troops, we hypothesise that the outcomes of sexual interactions may have been deemed fair since it was perceived by participants that the woman/girl benefited financially or materially from the interaction. Since the current research was not designed to address perceptions around exploitation and fairness, we could not explore this phenomenon further and recommend this as an area for future research.

These findings lead to several policy and programming recommendations. First, within PSOs it may be feasible to identify predictors of sexual misconduct to inform more targeted prevention of sexual exploitation and abuse (PSEA) initiatives. For instance, we have identified areas in eastern DRC with higher community reports of SEA and these could be targeted for increased training as well as closer surveillance around non-fraternisation policies. Furthermore, since the data highlight that civilian UN personnel were more likely to be implicated in narratives about sexual interactions, additional focused PSEA activities that are specific to civilians in the community in addition to enhanced PSEA strategies such as close monitoring of designated 'out-of-bounds' areas, and enforced patrols, could be considered. The second recommendation relates to reporting peacekeeper-perpetrated SEA. Since narratives involving sexual interactions with UN personnel were often deemed to have fair outcomes for the woman/girl, this may help to explain the gross underreporting of peacekeeper-perpetrated SEA in DRC. Great effort has been made by the UN to improve reporting through the development of community-based complaint networks (CBCNs) ${ }^{42}$ However, if affected women/girls are already perceived to have a fair outcome, this will likely disincentivise reporting to the UN, both by affected women/girls as well as by community members since there is likely a diminished sense of wrongdoing. Presumably, to broadly improve rates of formal SEA reporting, there must be some perceived benefit to doing so. However, with lengthy and complex investigations and a culture of impunity within which most SEA allegations fail to lead to reparations or justice, ${ }^{43}$ the perceived reporting benefit may be lacking for many host community members. Therefore, our second recommendation is 
that the UN should take these findings around perceived fairness into account when planning CBCNs, streamlining investigations and implementing survivor-centred support pathways. Alternate approaches may be needed given the limitations noted above for the current policies.

\section{Limitations and strengths}

The study has several notable limitations. First, despite attempts to collect narratives from a wide range of participants, the convenience sample was not representative and thus the results cannot be generalised. In addition, data regarding the exact numbers, locations, sizes and staffing of UN bases were quite limited and consequently, although we attempted to include a diverse sample of bases, we cannot confirm to what degree this was successful. Whether particular regions had higher or lower prevalences of peacekeeper-perpetrated SEA remains unknown as the data are not available. Second, recognising our positionality we are cognisant that as non-Congolese academics, the results are interpreted with our own inherent biases. While this article did not permit an opportunity to comprehensively present the qualitative data, more in-depth qualitative analysis is forthcoming in other publications. The research also has a number of noteworthy strengths including a relatively large sample size with 2865 self-interpreted narratives providing a wide range of perspectives from Congolese host community members. In addition, the lack of direct questioning about sexual interactions allowed narratives to emerge from the broader landscape of experiences and reduced social desirability bias while the opportunity for participants to interpret their own shared narratives reduced interpretation bias and may have revealed nuanced insights that would not have otherwise been identified.

\begin{abstract}
Acknowledgements We would like to thank the participants for sharing their experiences and for entrusting us to conduct this research. We would also like to express our sincere appreciation to Marakuja and SOFEPADI for their assistance in conducting this study. Many thanks to Ms Laurie Webster (QED Insight) and Ms Lesley Pablo for their assistance with the analysis, figures and tables, and we greatly appreciate Dr Melanie Walker's helpful comments on the manuscript. We are grateful to the Social Sciences and Humanities Research Council for their financial support. Lastly, we would like to share our heartfelt sympathies for the tragic loss of Ms Zawadi Mambo Albertine. As a SOFEPADI coordinator, Zawadi compassionately and tirelessly worked to empower women in the DRC. Without her, this research would not have been possible.
\end{abstract}

Contributors The study was designed by SAB and SLee, who also oversaw the original data collection in the DRC. SAB conducted the data analysis while SLee and SLusamba contributed to the interpretation. The manuscript was drafted by SB with input from SLee and SLusamba. All authors read and approved the final manuscript.

Funding This research was funded by the Social Sciences and Humanities Research Council of Canada, Insight Grant \#435-2017-1289 (SAB, Principal Investigator).

Competing interests None declared.

Patient consent for publication Not applicable.

Ethics approval This study was approved by the Queen's University Health Sciences and Affiliated Teaching Hospitals Research Ethics Board (protocol \# 6019042) and locally by the Congolese National Committee of Health Ethics (protocol \#001/ DP-SK/119PM/2018). Participants aged 13 to 17 were considered mature minors.
Parental consent was not obtained as it was believed that involving parents could have introduced bias and potentially parental conflict and/or abuse.

Provenance and peer review Not commissioned; externally peer reviewed.

Data availability statement Data are available on reasonable request. The dataset is available upon request to the corresponding author.

Supplemental material This content has been supplied by the author(s). It has not been vetted by BMJ Publishing Group Limited (BMJ) and may not have been peer-reviewed. Any opinions or recommendations discussed are solely those of the author(s) and are not endorsed by BMJ. BMJ disclaims all liability and responsibility arising from any reliance placed on the content. Where the content includes any translated material, BMJ does not warrant the accuracy and reliability of the translations (including but not limited to local regulations, clinical guidelines, terminology, drug names and drug dosages), and is not responsible for any error and/or omissions arising from translation and adaptation or otherwise.

Open access This is an open access article distributed in accordance with the Creative Commons Attribution Non Commercial (CC BY-NC 4.0) license, which permits others to distribute, remix, adapt, build upon this work non-commercially, and license their derivative works on different terms, provided the original work is properly cited, appropriate credit is given, any changes made indicated, and the use is non-commercial. See: http://creativecommons.org/licenses/by-nc/4.0/.

ORCID iD

Susan Andrea Bartels http://orcid.org/0000-0003-2782-3480

\section{REFERENCES}

1 Tull DM. Peacekeeping in the Democratic Republic of Congo: waging peace and fighting war. Int Peacekeep 2009;16:215-30.

2 Peterman A, Palermo T, Bredenkamp C. Estimates and determinants of sexual violence against women in the Democratic Republic of Congo. Am J Public Health 2011;101:1060-7.

3 Council on Foreign Relations. Global Conflict Tracker, 2021. Available: https://www.cfr.org/global-conflict-tracker/conflict/ violence-democratic-republic-congo

4 Johnson K, Scott J, Rughita B, et al. Association of sexual violence and human rights violations with physical and mental health in territories of the eastern Democratic Republic of the Congo. JAMA 2010;304:553-62.

5 Bartels SA, Scott JA, Mukwege D, et al. Patterns of sexual violence in Eastern Democratic Republic of Congo: reports from survivors presenting to Panzi Hospital in 2006. Confl Health 2010;4:9.

6 Bartels SA, Scott JA, Leaning J, et al. Sexual violence trends between 2004 and 2008 in South Kivu, Democratic Republic of Congo. Prehosp Disaster Med 2011;26:408-13.

7 Bartels S, Kelly J, Scott J, et al. Militarized sexual violence in South Kivu, Democratic Republic of Congo. J Interpers Violence 2013;28:340-58.

8 Kelly J, Vanrooyen M, Leaning J, et al. Characterizing sexual violence in the Democratic Republic of the Congo profiles of violence, community responses, and implications for the protection of women, 2009. Available: https://reliefweb.int/sites/reliefweb.int/ files/resources/47B2EF18D078C10E49257706000DC56B-Full_ Report.pdf

9 Kelly J. Rape in war: motives of militia in DRC, 2010. Available: https://www.usip.org/sites/default/files/SR243Kelly.pdf

10 United Nations Peacekeeping. MONUC Facts and Figures: United Nations, 2010. Available: https://peacekeeping.un.org/mission/past/ monuc/facts.shtml

11 United Nations Security C. Resolution 1925 (2010): adopted by the security council at its 6324th meeting on 28 May 2010, S/RES/1925, 2010. Available: https://digitallibrary.un.org/record/683422? In=en

12 United Nations Peacekeeping. MONUSCO Fact Sheet: United Nations, 2021. Available: https://peacekeeping.un.org/en/mission/ monusco

13 Holt K. DR Congo's Shameful Sex Secret London: BBC News, 2004. Available: http://news.bbc.co.uk/2/hi/africa/3769469.stm

14 Kent VL. Peacekeepers as perpetrators of abuse. African Security Review 2005;14:85-92.

15 Wax E. Congo's Desperate 'One-Dollar U.N. Girls': Shunned Teens, Many Raped by Militiamen, Sell Sex to Peacekeepers: Washington Post, 2005. Available: https://www.washingtonpost.com/wp-dyn/ articles/A52333-2005Mar20.html

16 Neudorfer K. Sexual exploitation and abuse in UN peacekeeping. London, UK: Lexington Books, 2015. 
17 United Nations General Assembly. Special measures for protection from sexual exploitation and sexual abuse. New York: United Nations, 2003. Available: https://reliefweb.int/sites/reliefweb.int/ files/resources/FE8016BAE4A9C2FB8525723B00711D69-UNSGspecial\%20measures-Oct03.pdf [Accessed cited 15 Apr 2021].

18 Grady K. Sex, statistics, peacekeepers and power: UN data on sexual exploitation and abuse and the quest for legal reform. Mod Law Rev 2016;79:931-60.

19 Wisdom J, Creswell JW. Mixed methods - integrating quantitative and qualitative data collection and analysis while studying patientcentered medical home models, 2013. Available: https://pcmh.ahrq. gov/sites/default/files/attachments/MixedMethods_032513comp.pdf [Accessed 10 Sep 2021].

20 Creswell JW, Plano Clark VL. Designing and conducting mixed methods research. Thousand Oaks, CA: Sage Publications, 2006.

21 Cognitive Edge. SenseMaker, 2017. Available: https://sensemaker. cognitive-edge.com

22 Webster L. Using Statistics to Help Interpret Patterns: Are My Eyes Tricking Me?2015. Available: http://qedinsight.com/2015/06/04/aremy-eyes-tricking-me/

23 Webster L, Carroll M. November 2014 Webinar: the art and science of story patterns, 2014. Available: http://qedinsight.com/resources/ library/november-2014-webinar/

24 DeLong S. Statistics in the triad, part I: geometric mean, 2016. Available: http://qedinsight.com/2016/03/28/geometric-mean/

25 DeLong S. Statistics in the triad, part II: Log-Ratio transformation, 2016. Available: http://qedinsight.com/2016/03/28/log-ratiotransformation/

26 Zou G. A modified Poisson regression approach to prospective studies with binary data. Am J Epidemiol 2004;159:702-6.

27 United Nations High Commissioner for R,. Save the Children UK. Exploitation: the experience of refugee children in guinea, Liberia and Sierra Leone based on initial findings and recommendations from assessment mission, 2002.

28 American Psychology Association. APA RESOLUTION on Support for the Expansion of Mature Minors' Ability to Participate in Research, 2018. Available: https://www.apa.org/about/policy/ resolution-minors-research.pdf

29 Nordås R, Rustad SCA. Sexual exploitation and abuse by peacekeepers: understanding variation. International Interactions 2013;39:511-34.

30 Moncrief S. Military socialization, disciplinary culture, and sexual violence in UN peacekeeping operations. J Peace Res 2017;54:715-30.

31 Vahedi L, Stuart $\mathrm{H}$, Etienne $\mathrm{S}$, et al. The distribution and consequences of sexual misconduct perpetrated by peacekeepers in Haiti: an exploratory cross-sectional analysis. International Journal of Environmental Research and Public Health. Under review.

32 King C, Lee S, Bartels SA. 'They were going to the beach, acting like tourists, drinking, chasing girls': a mixed-methods study on community perceptions of sexual exploitation and abuse by UN peacekeepers in Haiti. Sta 2020;9:10-22.

33 Lee S, Bartels S. 'They put a few coins in your hand to drop a baby in you': a study of peacekeeper-fathered children in Haiti. Int Peacekeep 2020;27:177-209.

34 Vahedi L, Bartels SA, Lee S. 'Even peacekeepers expect something in return': a qualitative analysis of sexual interactions between UN peacekeepers and female Haitians. Glob Public Health 2021;16:692-705.

35 Kolbe AR. 'It's not a gift when it comes with price': a qualitative study of transactional sex between UN peacekeepers and Haitian citizens. Stability 2015;4:1-26.

36 Beber B, Gilligan MJ, Guardado J, et al. Peacekeeping, compliance with international norms, and transactional sex in Monrovia, Liberia. Int Organ 2017;71:1-30.

37 Okigbo CC, McCarraher DR, Chen M, et al. Risk factors for transactional sex among young females in post-conflict Liberia. Afr J Reprod Health 2014;18:133-41.

38 Westendorf JK. Violating peace: sex, aid, and peacekeeping. 1st ed. Ithaca, New York: Cornell University Press, 2020: 232.

39 The World Bank. GDP per capita: The World Bank, 2019. Available: https://data.worldbank.org/indicator/NY.GDP.PCAP.CD?most recent_value_desc=false

40 United Nations Development Programme. Human Development Indicators - Democratic Republic of Congo: United Nations, 2020. Available: http://hdr.undp.org/en/countries/profiles/COD

41 Alexandra K. Peacekeepers' privilege and sexual abuse in postconflict populations. Peace Review 2011;23:369-76.

42 Inter-Agency Standing Committee. Best practice guide Inter-Agency community-based complaint mechanisms Protection against sexual exploitation and abuse, 2016. Available: https://interagencystand ingcommittee.org/system/files/best_practice_guide_inter_agency_ community_based_complaint_mechanisms_1.pdf

43 Awori T, Lutz C, Thapa PJ. Final report on expert mission to evaluate the risks to SEA prevention efforts in MINUSTAH, UNMIL, MONUSCO, and UNMISS, 2013. Available: https://static1. squarespace.com/static/514a0127e4b04d7440e8045d/t/599da7f7f5 e2310b13539b6b/1503504383454/20

44 REDRESS. Litigating Peacekeeper child sexual abuse: child rights international network, 2020. Available: https://redress.org/news/ obtaining-justice-through-courts-virtually-impossible-for-childvictims-of-peacekeeper-sexual-abuse-redress-and-crin-report/ 